\title{
Is Interpersonal Fairness in the Doctor-Patient Relationship Associated with Long-Term Compliance in Patients with Schizophrenia?*
}

\author{
Eva Jonas ${ }^{1}$, Guenter W. Maier ${ }^{2}$, Werner Kissling ${ }^{3}$, Johannes Hamann ${ }^{3}$ \\ ${ }^{1}$ Department of Psychology, University of Salzburg, Salzburg, Austria \\ ${ }^{2}$ Department of Psychology, Bielefeld University, Bielefeld, Germany \\ ${ }^{3}$ Psychiatric Department, Technical University Munich, Munich, Germany \\ Email: eva.jonas@sbg.ac.at
}

Received March 28 ${ }^{\text {th }}, 2013$; revised April 29 ${ }^{\text {th }}, 2013$; accepted May $26^{\text {th }}, 2013$

\begin{abstract}
Copyright (c) 2013 Eva Jonas et al. This is an open access article distributed under the Creative Commons Attribution License, which permits unrestricted use, distribution, and reproduction in any medium, provided the original work is properly cited.
\end{abstract}

\begin{abstract}
Does an interpersonal fair treatment of patients with schizophrenia by their hospital psychiatrists improve patients' intentions to take the antipsychotic medicine when leaving the hospital, long-term compliance and the perceived quality of medical treatment? 71 acutely ill in-patients with a diagnosis of schizophrenia and their doctors were included in this study. At hospital discharge patients received a questionnaire measuring their interpersonal fairness perceptions, the perceived quality of medical treatment, and intention to take the medicine. After 6 month we also measured patients' long-term compliance. Data were analyzed by correlational analyses and path model. The results indicated that interpersonal fairness increased patients' long-term compliance, which was mediated by the intention to take the medicine when leaving the hospital and the perceived quality of medical attendance. Thus, without consuming more time, an interpersonal fair treatment of patients by their doctors seems to have beneficial effects on patients' perceived quality of medical care and long-term compliance. Theoretical and practical implications of the results are briefly discussed.
\end{abstract}

Keywords: Interpersonal Fairness; Schizophrenia; Therapeutic Relationship; Adherence; Compliance; Justice

\section{Introduction}

Psychiatric patients see the therapeutic relationship as the most valuable part of satisfactory psychiatric care (Johansson \& Eklund, 2003). Even more importantly, individuals who view their treatment and the therapeutic relationship more positively are more likely to have better treatment results, which include less severe symptoms, a lower rate of rehospitalization, and higher quality of life, as well as better social functioning (e.g., Frank \& Gunderson, 1990; Hewitt \& Coffey, 2005; Priebe \& Gruyters, 1995). Thus, a superior therapeutic relationship seems to cause patients to be more accepting of their treatment, which then positively influences the overall outcome (Chue, 2006). This is especially the case for patients with schizophrenia (Kikkert et al., 2006; Misdrahi, Verdoux, Lancon, \& Bayle, 2009; Misdrahi, Petit, Blanc, Bayle, \& Llorca, 2012).

Despite the importance attributed to the therapeutic alliance there is relatively little knowledge as to what actually constitutes good therapeutic alliance or to how psychiatrists should communicate with their patients (McCabe \& Priebe, 2008).

\footnotetext{
*Financal Discolsure: Dr. Hamann has received honoraria and/or research support from Janssen-Cilag, Eli Lilly, Astra Zeneca, and Otsuka. Dr. Kissling has received honoraria from Janssen-Cilag, San-ofi-Aventis, Johnson \& Johnson, Pfizer, Bristol-Myers Squibb, AstraZeneca, Lundbeck, Novartis, and Eli Lilly.
}

Recent research has emphasized on procedural fairness that is, how fair do patients perceive the procedures undertaken? Here, most notably the issues of coercion and hospital admission (e.g., Day et al., 2005; Galon \& Wineman, 2010; Jaeger \& Rossler, 2010; Lidz et al., 1998) and of shared decision making (e.g., Hamann, Leucht, \& Kissling, 2003) have been investigated. Surprisingly little attention has been paid to interpersonal fairness, that is, whether patients feel treated with respect, politeness and dignity.

\section{The Concept of Interpersonal Fairness}

Research from different areas in psychology shows that fairness in various situations in daily professional and private life affects a wide range of human emotion, attitude and behavior. For example in organizational psychology research differentiates between four aspects of fairness: distributive (how fair are resources distributed?), procedural (how fair are the used procedures?), informational (is the provision of information adequate?) and interpersonal fairness (Colquitt, Conlon, Wesson, Porter, \& Ng, 2001). Interpersonal fairness (Greenberg, 1993) refers to the interpersonal treatment in an organization, typically by the supervisor, for example do people feel they are treated with respect and propriety? Interpersonal fairness positively influences psychological outcomes such as evaluation of 
an authority, job satisfaction, well-being, affective commitment toward the company and organizational citizenship behavior (Colquitt et al., 2001). Interpersonal fairness and the quality of the relationship between supervisors and subordinates are strongly related (Roch \& Shanock, 2006).

In psychiatric research fairness is also an important topic, although the focus has been more on procedural justice. Several studies, especially in the context of civil commitment hearings ${ }^{1}$ suggest that the procedural fairness patients perceive is a major issue in the context of psychiatric treatment. For example, it was found that patients who thought their point of view had been heard and taken into consideration (Susman, 1994), that is, who experienced procedural justice, rated the process as more fair than patients who did not feel like they had been heard sufficiently or taken seriously. Procedural fairness and the ratings of outcome fairness were also strongly related.

Yet, interpersonal fairness has also been shown to be important in the context of civil commitment hearings. To many patients testifying psychiatrists, state attorneys, and judges appeared to be disrespectful, untrusting and disinterested (Greer, O'Regan, \& Traverso, 1996). In addition, the testimony of the psychiatrist often discloses private information concerning the details of the patients' illness, which leads to embarrassment on the side of the patient. Along with Tyler we suggest that cooperation can be improved by the way mentally ill persons view their participation, the treatment of their dignity, and trust during such hearings (Tyler, 1992). The respectful and dignified treatment of respondents by legal authorities during hearings, as well as a chance at stating their case (i.e., voice), may cause patients to be more agreeable to the notion of involuntary commitment. This may then lead to a domino effect, as this kind of acceptance may increase their participation within the therapeutic environment and, ultimately, incidents of aggressive behavior that necessitate seclusion and restraints may even decrease (Cascardi, Poythress, \& Hall, 2000).

Yet, with regard to the perceived fairness during psychiatric hospital admissions the picture may be different. In one study it was, for example, found that $80 \%$ of participants were treated with "fairness" in the admission process-whereby the voluntary sample perceived having been treated significantly more fairly than the involuntary sample (McKenna, Simpson, Coverdake, \& Laidlaw, 2001). Does this render fairness to be a less important topic when looking at the stay in the hospital? We think not. There is evidence that procedural justice can significantly lessen the perception of coercion during hospital admission (Galon \& Wineman, 2010). However, what about interpersonal fairness regarding the doctor's behavior? Building on the research reported above on the findings of interpersonal fairness in organizations we predict that interpersonal fairness in the doctor-patient relationship also positively affects the patients' attitude towards their medication and compliance behavior. However, what does this mean in specific? Can doctors influence the patients' compliance by just being polite, respectful and considerate of the patients' dignity?

Interpersonal fairness is part of the doctor's conduct toward the patient but the crucial point is how fair the doctor's conduct is subjectively perceived by the patient. We propose that the perception of fairness increases the patients' motivation to take

${ }^{1}$ In civil commitment hearings a decision is made regarding whether or not a person who is mentally ill and who might be a danger to him/herself or others and/or who might be unable to care for him/herself without the help of another person needs an involuntary psychiatric hospitalization. their medicine after they have left the hospital because the perception of fairness should increase the patients' perception of quality of the medical treatment and their intention (to take the medication), which has been shown to be an immediate anticipant of behavior (Ajzen, 1991); both of which should then increase the patients' long-term compliance to follow the recommended treatment.

Finally, one might ask whether interpersonal fair treatment is doable. Do doctors have sufficient time for a fair treatment of their patients-considering the high workload of doctors in the German health system? Yet, does it actually take longer to treat patients with interpersonal fairness?

It was the aim of the present analysis to test the hypothesis that an interpersonal fair treatment of patients with schizophrenia increases patients' long-term compliance. In addition we investigated whether this effect was mediated by patients' intention to take the recommended medicine when leaving the hospital and their perception of the quality of medical treatment. Finally, we tested whether it actually took longer to treat patients with interpersonal fairness.

\section{Method}

Seventy one acutely ill in-patients (37 [52.1\%] women, 34 $[47.9 \%]$ men) with a diagnosis of schizophrenia and their doctors were included in this study.

The study took place from February 2003 to January 2004 in two psychiatric state hospitals in Germany. The data collection was embedded in a larger interventional study on a shared decision making program on antipsychotic drug choice (Hamann et al., 2006; Hamann, Cohen, Leucht, Busch, \& Kissling, 2007). For the present analysis we used all patients with complete data irrespectively to their allocation (intervention/control group) in the original trial.

On average, the participants were 37.7 years old $(\mathrm{SD}=11.4$, range: $21-64$ years), they had been ill for 9.6 years $(\mathrm{SD}=$ 9.17), had been hospitalized with schizophrenia for 4 times (SD $=5$ ) (including the present stay), $22(31 \%)$ had been treated because of compulsory admission, and they had stayed on average for 14 days $(\mathrm{SD}=9)$ on the ward when the study began and for 33 days $(\mathrm{SD}=28)$ when they were discharged. The following measures were applied before hospital discharge: Interpersonal fairness. As the independent variable, three items adapted from the scale interpersonal justice of the German version of organizational justice scales (Maier, Streicher, Jonas \& Woschée, 2007) were used (i.e., To what extent has the physician treated you 1) in a polite manner, 2) with dignity, 3) with respect). The items were measured with scales ranging from 1 (not at all) to 5 (absolutely), Cronbach's alpha $=.83$.

Dependent variables. At the time of discharge from hospital (time 1), patients were asked to complete the following scales: 1) A self-report measure of the patients' intention to take their medication, which consisted of four self-constructed items with scales ranging from 1 (totally disagree) to 5 (totally agree) (Items: I am firmly committed to take the medication. I will continue to take the medication in any case. I can well imagine to autonomously stop the mediation one day (inverted). I will surely never autonomously stop the medication), Cronbach's alpha $=.70$;

2) Perceived quality of treatment, which was assessed with 8 items (e.g., How would you judge the quality of treatment you received?), on scales ranging from 1 (low quality) to 4 (high 
quality), Cronbach's alpha $=.90$ (Langewitz, Keller, Denz, Wossmer-Buntschu, \& Kiss, 1995). In addition, we asked the physicians how time intensive the therapeutical care of this patient was compared to others $(1=$ much below average to $5=$ much above average).

At the 6-months follow up the following data were obtained: As an indicator of long-term compliance with medication 6 months after discharge, a rating was used based on 1) patients' self report (MARS Scale) (Thompson, Kulkarni, \& Sergejew, $2000)$, 2) ratings from the outpatient psychiatrists of compliance of their patients on a 4-point scale raging from "poor compliance" to "very good compliance", and 3) physicians were also asked to make unannounced measures of plasma levels of the prescribed anti-psychotics from the patients 6 months after discharge (to which patients had signed informed consent during the index hospitalization). For the 6-month follow-up there were $n=22$ plasma levels available. Overall compliance was considered "good" (high compliance rated as 1) if patient and physician agreed in their (positive) estimates. In all other cases (incongruence of ratings, both rating poor compliance) compliance was rated as "poor" (low compliance rated as 0). Results were corrected in the direction towards the results of the plasma level evaluation if plasma levels indicated compliance or noncompliance different from that derived from self-rating/physicians' rating (in $\mathrm{n}=2$ cases). The study was approved by the ethics committee of the Technical University Munich.

\section{Results}

The descriptive statistics and correlations are displayed in Table 1. We tested our mediation hypotheses following the criteria suggested by Baron and Kenny (1986). The correlations between interpersonal fairness and each of the two mediators (intention to take the medication and quality of treatment) were significant. Furthermore, the correlation between the mediator and the criteria follow-up compliance with medication was significant with regard to intention to take the medication and marginal when it comes to quality of treatment. Thus, the requirements for a mediation effect were met. In order to test the indirect effect, we conducted a path model using MPlus 4.2. As the criterion was binary, parameters were estimated by the WLSMV method (weighted least squares with robust standard errors, mean and variances adjusted).

The correlation analysis showed the more interpersonally fair the patients judged the behavior of their doctor, the stronger their self-reported intention to take the medication when leaving the hospital, $\mathrm{r}=.41, p<.001$, the higher patients' perception of the quality of the treatment they had received in the hospital, $\mathrm{r}=.44, p<.001$, and the stronger their long-term compliance, $r=.27, p<.03$. Moreover, quality of treatment was also positively associated with the intention to take the medication, $\mathrm{r}=.46, p<.001$ and long-term compliance, $\mathrm{r}=.23, p$ $<.06$. Finally, also intention to take the medication was correlated with long-term compliance, $\mathrm{r}=.41, p<.001$.

The indirect effect of interpersonal fairness on the follow-up rating of compliance mediated by self-reported intention to take the medication at discharge from hospital was .21, $p<.01$. The indirect effect of interpersonal fairness on the follow-up rating of compliance mediated by quality of treatment at discharge from hospital was .09, $p<.10$ (Figure 1).

Finally, with regard to time intenseness correlation analyses showed that it did not take the doctors longer to treat their pa-

Table 1.

Means, standard deviations, reliabilities and intercorrelations of study variables.

\begin{tabular}{cccccccc}
\hline & Variable & M & SD & 1 & 2 & 3 \\
\hline 1 & Interpersonal fairness & 4.45 & .62 & $(.83)$ & & & \\
2 & Quality of the treatment & 3.14 & .59 & $.44^{* * *}$ & $(.90)$ & & \\
3 & Intention to take the medication & 4.15 & .94 & $.41^{* * *}$ & $.46^{* * *}$ & $(.70)$ & $.41^{* * *}$ \\
4 & Long-term compliance & .46 & .50 & $.27^{*}$ & $.23^{+}$ & .11 & .02 \\
5 & Time intenseness $^{\mathrm{a}}$ & 3.29 & .62 & .10 & -.01 & .11 \\
\hline
\end{tabular}

Note: $\mathrm{N}=71 .{ }^{\mathrm{a}} \mathrm{N}=69$ because of missing data. Values in parentheses along the diagonal indicate reliability estimates $\left(\mathrm{Cronbach}\right.$ 's Alpha). ${ }^{* * *} p<.001 ;{ }^{* *} p<.01 ;{ }^{*} p=<.05 ;{ }^{+} p$ $<.06$ (two-tailed).

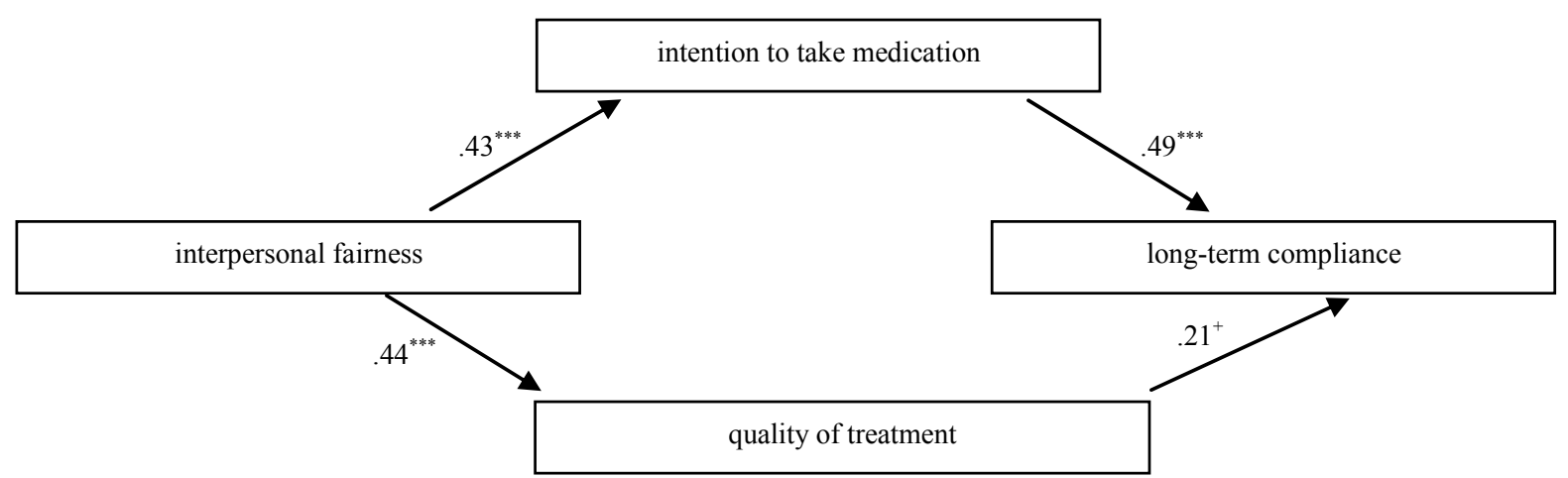

Figure 1.

Pathmodel with standardized coefficients. ${ }^{* * *} p<.001 ;{ }^{+} p<.09$. 
tients fairly, $\mathrm{r}=.10, p>.40$; patients did not perceive the quality of treatment to be higher when they had spent more time with their doctor, $\mathrm{r}=-.01, p>.90$, nor did their intention to take the medication, $\mathrm{r}=.11, p>.35$, or their long-term compliance $\mathrm{r}=.02, p>.85$ depend on the time the doctors spent for the treatment.

\section{Discussion}

The results supported our hypotheses: Interpersonal fairness was shown to increase patients' long-term compliance with medication, which was mediated by their intention to take the medication when leaving the hospital and the perceived quality of treatment in the hospital. Moreover, a fairer treatment was not associated with the length of interaction the doctor had with the patients.

We think these results have important implications. There is a body of literature on patient compliance in schizophrenia treatment (e.g., Fenton, Blyler, \& Heinssen, 1997) suggesting that compliance is a complex issue. Elaborate interventions to improve compliance have been developed and have proven their efficacy (e.g., Velligan et al., 2010). However, our evidence also suggests that the simple fact whether a patient feels treated in a polite manner might make a difference when it comes to acceptance of and adherence with medication. As research by Hamann et al. (2011) suggests the stronger participants' perception of fairness the less important it seems to them to be involved in participating in the medical decision process. And in fact, our results even showed that there is an association between interpersonal fairness and long-term compliance. This association is mediated by patients' intention at discharge whether they want to pursue with their medication or not, which was positively influenced by the perception of interpersonal fairness regarding their doctor's behavior.

With regard to theoretical implications the therapeutic relationship has been proven to be crucial for achieving good treatment results (e.g., Chue, 2006; Frank \& Gunderson, 1990; Hewitt \& Coffey, 2005; Priebe \& Gruyters, 1995). However, what constitutes a good therapeutic relationship and which theoretical concepts help to understand the therapeutic relationship? Our research suggests that the perception of interpersonal fairness might play an especially important role in constituting a good therapeutic relationship. Further research is needed to better understand how the concept of interpersonal fairness is related to other aspects constituting a good therapeutic relationship and which aspect is crucial in achieving longterm compliance among patients.

Our findings also have important practical implications. First, physicians as well as other staff members must be aware that despite the complexity of a hospital stay and despite the proven efficacy of other therapeutic strategies patients appear to be strongly influenced by a seemingly small variable - how staff talks to them. Thus, the awareness of psychiatrists that they offer a service to patients and that client satisfaction is one major goal of service provision should be adopted more thoroughly in clinical practice. Probably this issue is often neglected under time pressure but it is important to keep in mind that interpersonal fairness (e.g. to apologize for a delay, to accept complaints) is necessary and influences long-term outcomes. As shown, interpersonal fairness is also doable since it did not cost the psychiatrists in our study more time. Second, obviously the quality of long-term compliance is in part already certain at the time of discharge, showing the necessity to pick up the issue of compliance in therapeutic communication already during hospital stay.

\section{Limitations}

The significance of our results is limited since we undertook a post hoc analysis. In addition psychiatrists behavior with regard to interpersonal fairness was not manipulated which also limits our ability to draw causal conclusions.

\section{Conclusion}

An interpersonally fair treatment of patients by their doctors seems to be very beneficial. Without consuming more time of interaction it increases the perceived quality of medical treatment and also improves long-term compliance and is thus expected to reduce re-hospitalizations.

\section{Acknowledgements}

The authors would like to thank all participating patients and physicians. The trial was funded by the German Ministry of Health and Social Security (217-43794-5/9) within the funding project "Der Patient als Partner im medizinischen Entscheidungsprozess".

\section{REFERENCES}

Ajzen, I. (1991). Theory of planned behavior. Organizational Behavior and Human Decision Processes, 50, 179-211. doi:10.1016/0749-5978(91)90020-T

Baron, R. M., \& Kenny, D. A. (1986). The moderator-mediator variable distinction in social psychological research: Conceptual, strategic, and statistical considerations. Journal of Personality and Social Psychology, 51, 1173-1182. doi:10.1037/0022-3514.51.6.1173

Cascardi, M., Poythress, N. G., \& Hall, A. (2000). Procedural justice in the context of civil commitment: An analogue study. Behavioral Science and the Law, 18, 731-740. doi:10.1002/bsl.421

Chue, P. (2006). The relationship between patient satisfaction and treatment outcomes in schizophrenia. Journal of Psychopharmacology, 20, 38-56. doi:10.1177/1359786806071246

Colquitt, J. A., Conlon, D. E., Wesson, M. J., Porter, C. O., \& Ng, K. Y. (2001). Justice at the Millennium: A meta-analytic review of 25 years of organizational justice research. Journal of Applied Psychology, 86, 425-445. doi:10.1037/0021-9010.86.3.425

Day, J. C., Bentall, R., Roberts, C., Randall, F., Rogers, A., Cattell, D., \& Power, C. (2005). Attitudes toward antipsychotic medication: The impact of clinical variables and relationships with health professionals. Archives of General Psychiatry, 62, 717-724. doi:10.1001/archpsyc.62.7.717

Fenton, W. S., Blyler, C. R., \& Heinssen, R. K. (1997). Determinants of medication compliance in schizophrenia: Empirical and clinical findings. Schizophrenia Bulletin, 23, 637-651. doi: $10.1093 / \mathrm{schbul} / 23.4 .637$

Frank, A. F., \& Gunderson, J. G. (1990). The role of the therapeutic alliance in the treatment of schizophrenia. Archives of General Psychiatry, 47, 228-236. doi:10.1001/archpsyc.1990.01810150028006

Galon, P. A., \& Wineman, N. M. (2010). Coercion and procedural justice in psychiatric care: State of the science and implications for nursing. Archives of Psychiatric Nursing, 24, 307-316. doi:10.1016/j.apnu.2009.12.005

Greenberg, J. (1993). The social side of fairness: Interpersonal and informational classes of organizational justice. In R. Cropanzano (Ed.), Justice in the workplace: Approaching fairness in human resource management (pp. 79-103). Hillsdale, NJ: Erlbaum.

Greer, A., O’Regan, M., \& Traverso, A. (1996). Therapeutic jurispru- 
dence and patients' perceptions of procedural due process of civil commitment hearings. In D. Wexler, \& B. Winnick (Eds.), Law in a therapeutic key: Developments in therapeutic jurisprudence (pp. 923-934). Durham, NC: Carolina Academic Press.

Hamann, J., Cohen, C., Leucht, S., Busch, R., \& Kissling, W. (2007). Shared decision making and long term outcome in schizophrenia treatment. Journal of Clinical Psychiatry, 68, 992-997. doi:10.4088/JCP.v68n0703

Hamann, J., Langer, B., Winkler, V., Busch, R., Cohen, R., Leucht, S., \& Kissling, W. (2006). Shared decision making for in-patients with schizophrenia. Acta Psychiatrica Scandinavica, 114, 265-273. doi:10.1111/j.1600-0447.2006.00798.x

Hamann, J., Leucht, S., \& Kissling, W. (2003). Shared decision making in psychiatry. Acta Psychiatrica Scandinavica, 107, 403-409. doi:10.1034/j.1600-0447.2003.00130.x

Hamann, J., Mendel, R., Reiter, S., Cohen, R. Bühner, M., Schebitz, M., \& Berthele, A. (2011). Why do some patients with schizophrenia want to be engaged in medical decision making and others do not? The Journal of Clinical Psychiatry, 72, 1636-1643. doi:10.4088/JCP.10m06119yel

Hewitt, J., \& Coffey, M. (2005). Therapeutic working relationships with people with schizophrenia: Literature review. Journal of Advanced Nursing, 52, 561-570. doi:10.1111/j.1365-2648.2005.03623.x

Jaeger, M., \& Rossler, W. (2010). Enhancement of outpatient treatment adherence: Patients' perceptions of coercion, fairness and effectiveness. Psychiatry Research, 180, 48-53. doi:10.1016/j.psychres.2009.09.011

Johansson, H., \& Eklund, M. (2003). Patients' opinion on what constitutes good psychiatric care. Scandinavian Journal of Caring Sciences, 17, 339-346. doi:10.1046/j.0283-9318.2003.00233.x

Kikkert, M. J., Schene, A. H., Koeter, M. W., Robson, D., Born, A., Helm, H., \& Gray, R. J. (2006). Medication adherence in schizophrenia: Exploring patients', carers' and professionals' views. Schizophrenia Bulletin, 32, 786-794. doi:10.1093/schbul/sbl011

Langewitz, W., Keller, A., Denz, M., Wossmer-Buntschu, B., \& Kiss, A. (1995). The patient satisfaction questionnaire: A suitable tool for quality control in the physician-patient relationship? Psychotherapie, Psychosomatik, Medizinische Psychologie, 45, 351-357.

Lidz, C. W., Mulvey, E. P., Hoge, S. K., Kirsch, B. L., Monahan J., Eisenberg, M., \& Roth, L. (1998). Factual sources of psychiatric patients' perceptions of coercion in the hospital admission process. The American Journal of Psychiatry, 155, 1254-1260
Maier, G. W., Streicher, B., Jonas, E., \& Woschée, R. (2007). Gerechtigkeitseinschätzungen in organisationen: Die validität einer deutschsprachigen fassung des fragebogens von colquitt. Diagnostica, 53, 97-108. doi:10.1026/0012-1924.53.2.97

McCabe, R., \& Priebe, S. (2008). Communication and psychosis: It's good to talk, but how? British Journal of Psychiatry, 192, 404-405. doi:10.1192/bjp.bp.107.048678

McKenna, B. G., Simpson, A. I., Coverdake, J. H., \& Laidlaw, T. M. (2001). An analysis of procedural justice during psychiatric hospital admission. International Journal of Law and Psychiatry, 24, 573581. doi:10.1016/S0160-2527(00)00069-8

Misdrahi, D., Petit, M., Blanc, O., Bayle, F., \& Llorca, P. M. (2012). The influence of therapeutic alliance and insight on medication adherence in schizophrenia. Nordic Journal of Psychiatry, 66, 49-54. doi: $10.3109 / 08039488.2011 .598556$

Misdrahi, D., Verdoux, H., Lancon, C., \& Bayle, F. (2009). The 4-Point ordinal Alliance Self-report: A self-report questionnaire for assessing therapeutic relationships in routine mental health. Comprehensive Psychiatry, 50, 181-185. doi:10.1016/j.comppsych.2008.06.010

Priebe, S., \& Gruyters, T. (1995). Patients' assessment of treatment predicting outcome. Schizophrenia Bulletin, 21, 87-94. doi: $10.1093 /$ schbul $/ 21.1 .87$

Roch, S. R., \& Shanock, L. R. (2006). Organizational justice in an exchange framework: Clarifying organizational justice distinctions. Journal of Management, 32, 299-322. doi:10.1177/0149206305280115

Susman, J. (1994). Resolving hospital conflicts: A study on therapeutic jurisprudence. Journal of Psychiatry and Law, 23, 107-133.

Thompson, K., Kulkarni, J., \& Sergejew, A. (2000). Reliability and validity of a new Medication Adherence Rating Scale (MARS) for the psychoses. Schizophrenia Research, 42, 241-247. doi:10.1016/S0920-9964(99)00130-9

Tyler, T. R. (1992). The psychological consequences of judicial procedures: Implications for civil commitment. SMU Law Review, 46, 433-445.

Velligan, D. I., Weiden, P. J., Sajatovic, M., Scott, J., Carpenter, D., Ross, R., \& Docherty, J. P. (2010). Strategies for addressing adherence problems in patients with serious and persistent mental illness: Recommendations from the expert consensus guidelines. Journal of Psychiatric Practice, 16, 306-324.

doi:10.1097/01.pra.0000388626.98662.a0 